\title{
READERS
Insight
}

Journal of Economic Info (JEI)

ISSN:2313-335X

www.readersinsight.net/jei

\section{Examination of random walk hypothesis in beverages sector of Pakistan}

\author{
Syeda Anam Hassan ${ }^{1 *}$ \\ ${ }^{1}$ Department of Management Sciences, COMSATS Institute of Information Technology \\ * Corresponding author: syedaanam6695@gmail.com
}

\begin{abstract}
The objective of the study is to examine the random walk hypothesis in three largest industries of Pakistan namely, Murree Brewery, Shezan International and Nirala MSR Foods limited. The results show that Bevarges sector do not follow the Random Walk Hypothesis. The results conclude that investors may predict the future outcome of stocks. The risk minimization strategy and profitable mode to purchase share of Shehzan International especially in the start of every month and sell them in end days of month.
\end{abstract}

ARTICLE INFORMATION

\section{Received: 14 February 2014 \\ Revised: $\quad 17$ April 2014 \\ Accepted: 25 April 2014}

\section{Introduction}

The beverage industry is a huge part of our economy that affects many different sectors. Successful maneuvering through this sector is highly competitive arena that takes experience and knowledge. Experts of Beverage industry handle all aspects of the processes that are involved in taking successful ideas from concept to market. The beverage sectors contribute more than $1.9 \%$ of total market capitalization. Beverages industry is involved in processing raw food materials, packaging, and distributing them. This includes fresh, prepared foods as well as packaged foods, and alcoholic and nonalcoholic beverages. In Pakistan there are three listed companies in KSE are:

i. The Murree Brewery Company Limited.

ii. Shezan International Limited.

iii. Nirala MSR Foods Limited.

The Murree Brewery Company Ltd was established in 1860 in response to the ever increasing demand for beer by the personnel of the British Raj and currently the oldest continuing enterprise in Pakistan. Its products are only legally available in Pakistan owing to a prohibition on the exportation of alcohol from Pakistan. The Company is principally engaged in the manufacturing of Pakistan made foreign liquor (PMFL) including alcoholic beer, non-alcoholic beer (NAB), non-alcoholic products (NAP), which includes juices in tetra packs in Rawalpindi and food products, juices, glass bottles and jars in Hattar. Its shares were traded on the Calcutta Stock Exchange as early as 1902 and in 1960 as an oldest firm continuing industrial enterprise of Pakistan. A division of the company also produces and markets fruit juices in Pakistan. Its total annual sales in year 2013 were about Rs. 2.3 billion ( $\$ 28$ million). The Shezan International Limited was incorporated in 1964 as a Private Limited Company in leading manufacturer of juices, beverages, squashes, sherbets, jams and preserves derived from fresh fruits and vegetables. It has three large manufacturing plants located in Karachi, Lahore and Hattar. Today Shezan is one of the most recognized brand names in Pakistan synonymous with quality products and available in more than $90 \%$ of the households. Shezan's product range is over 80 products and still growing. Shezan is having most suitable location for export to Afghanistan, Central Asian States, UK, USA, Europe, Southeast Asia, Japan and other countries. The company was listed on the Lahore Stock Exchanges on October10, 1988 and Karachi Stock Exchanges during July 1989.

The great journey started when Taj Din migrated from Amritsar, India, to Lahore and started a small breakfast shop in the inner city of Lahore. The business of Nirala Sweets, in just over half a century, has evolved into a Group of Companies, consisting of various business divisions. It is heartening to see that from a single, small mithai shop in old Lahore in 1948, the Company now owns 20 factories in 6 cities of Pakistan, besides 2 in the UAE. The Group consists of businesses like dairy processing and packaging, snacks, restaurants, software house and more recently, automobiles. The old name was Shakarganj Foods Limited - (SKFL) to Nirala MSR Foods Limited - (NMFL) in December 10, 2013.

\section{Literature review}

Random Walk is the path of a variable over time that exhibits no predictable patterns at all. If a price, $\mathrm{p}$, moves in a random walk, the value of $p$ in any period will be equal to the value of $p$ in the period before, plus or minus some random variable. A follower of the random walk theory believes it's impossible to outperform the market without assuming additional risk. The random walk model was first developed by Bachelier (1900) in which he asserted that successive price changes between two periods is independent with zero mean and its variance is proportional to the interval between the two time periods. Kim, Nelson \& Startz (1991) examined the random walk process of stock prices by using weekly and monthly returns in five Pacific-Basin stock markets. The findings provided evidence that the mean reversion was only a phenomenon of the pre-World War II period, and not a feature of the post-war period. They found that the variance ratio tests produced positive serial correlation. Wu (1996) used the serial correlation test on 8 and 12 individual shares for the period from June 1992 through December 1993 for the Shanghai and Shenzhen markets respectively and argued that CSMs seem weakform efficient. Mookerjee and Yu (1999) only tested two market indices (Shanghai and Shenzhen) using the serial correlation and runs 
tests, but concluded the markets were inefficient. They concentrated their investigation of the market behaviour on the period from December 1990 to May 1992 and from May 1992 to December 1993. Guru (2000) showed that variance ratio and multiple variance ratio tests reject random walk for beverage sector listed in Kuala Lampur stock exchange. They further show that trading rules like variable length moving average (VMA) and fixed length moving average (FMA) have predictive ability of earning profits over and above the transaction costs. Darrat \& Zhong (2000) examined random walk hypothesis for the two newly created stock exchanges in China. They followed two different approaches-the variance ratio test and comparison of NAÏVE model (based on assumption of random walk) with other models like ARIMA and GARCH. They rejected the random walk in newly created Chinese stoke exchanges using both the methodologies. They further suggested artificial neural network (ANN) based models as strong tools for predicting prices in the stock exchanges of developing countries. Pant and Bishnoi (2002) analyzed the behavior of daily and weekly returns of five Indian's Beverage and Food stock market indices for random walk during April-1996 to June-2001. They tested the indices for normality, autocorrelation using Q-statistic \& Dickey-Fuller test and analyzed variance ratio using homoscedastic and heteroscedastic test estimates. The results support that Indian Beverage and Food stock market indices do not follow random walk. Heteroscedasticity is not a cause of non-random behavior while autocorrelation is a minor source of no random walk indicating thereby that mean reverting behavior of stock indices is the major cause of random walk. While results of variance ratio test and autocorrelation test are similar and reject random walk in Indian Beverage and Food stock market indices, the results from DickeyFuller test fail to reject the null hypothesis of random walk. Moreover
Irfan et al., (2010) in their study on Karachi stock market explored that in some way random walk follows but in general the random walk behavior do not followed by Karachi Stock Market. Mehmood et al., (2012) analyzed three year financial data of KSE-100 Index, employing ADF, PP and autocorrelation test, their result revealed that Pakistani market is an efficient market, no opportunity for technical analyst. Mishra et al (2014) tests the random walk hypothesis for the Indian stock market. Using 19 years of monthly data on six indices from the National Stock Exchange (NSE) and the Bombay Stock Exchange (BSE), this study applies three different unit root tests with two structural breaks to analyze the random walk hypothesis. The result shows that unit root tests that allow for two structural breaks alone are not able to reject the unit root null; however, a recently developed unit root test that simultaneously accounts for heteroscedasticity and structural breaks, finds that the stock indices are mean reverting. Furthermore, the results point out the importance of addressing heteroscedasticity when testing for a random walk with high frequency financial data.

\section{Methodology and results}

Some tests have been developed for testing the random walk hypothesis. Cowles-Jones statistic (Cowles \& Jones, 1937) and run test, Q-statistic (and Q'-statistic) and Variance-Ratio Test etc. In this study Predictive (OLS) Jarret (2008) model has been employed to check the random behavior of share prices. The simplest random walk hypothesis is the independent and identically distributed (IID) increments.

Table 1: Predictive (OLS) Jarret (2008) model

\begin{tabular}{|c|c|c|c|c|c|c|}
\hline & Companies & Coefficient & Std. Error & t. Stats (Prob) & Adj. $R^{2}$ & Results \\
\hline \multirow[t]{3}{*}{ January } & $\mathrm{MB}$ & $0.962339^{*}$ & 0.032701 & $\begin{array}{l}29.42831 \\
(0.0000)\end{array}$ & 0.976299 & No Random Walk \\
\hline & NF & $0.920339^{*}$ & 0.050527 & $\begin{array}{l}18.21491 \\
(0.0000)\end{array}$ & 0.940304 & No Random Walk \\
\hline & SI & $0.914380^{*}$ & 0.076511 & $\begin{array}{l}11.95092 \\
(0.0000)\end{array}$ & 0.871027 & No Random Walk \\
\hline \multirow[t]{3}{*}{ February } & MB & $0.930957^{*}$ & 0.091492 & $\begin{array}{l}10.17533 \\
(0.0000)\end{array}$ & 0.850669 & No Random Walk \\
\hline & NF & $0.919692^{*}$ & 0.067436 & $\begin{array}{l}13.63805 \\
(0.0000)\end{array}$ & 0.916255 & No Random Walk \\
\hline & SI & $0.808378^{*}$ & 0.113037 & $\begin{array}{l}7.151435 \\
(0.0000)\end{array}$ & 0.735850 & No Random Walk \\
\hline \multirow[t]{3}{*}{ March } & MB & $0.807112^{*}$ & 0.170337 & $\begin{array}{l}4.738324 \\
(0.0002)\end{array}$ & 0.530304 & No Random Walk \\
\hline & NF & $0.989863^{*}$ & 0.102265 & $\begin{array}{l}9.679410 \\
(0.0000)\end{array}$ & 0.829888 & No Random Walk \\
\hline & SI & $1.011282^{*}$ & 0.118483 & $\begin{array}{l}8.535241 \\
(0.0000)\end{array}$ & 0.790865 & No Random Walk \\
\hline \multirow[t]{3}{*}{ April } & MB & $0.949658^{*}$ & 0.052720 & $\begin{array}{l}18.01336 \\
(0.0000)\end{array}$ & 0.941773 & No Random Walk \\
\hline & NF & $0.930775^{\star}$ & 0.082624 & $\begin{array}{l}11.26512 \\
(0.0000)\end{array}$ & 0.862923 & No Random Walk \\
\hline & SI & $0.664063^{*}$ & 0.164890 & $\begin{array}{l}4.027308 \\
(0.0007)\end{array}$ & 0.432128 & No Random Walk \\
\hline \multirow[t]{3}{*}{ May } & MB & $0.972043^{*}$ & 0.043243 & $\begin{array}{l}22.47881 \\
(0.0000)\end{array}$ & 0.961854 & No Random Walk \\
\hline & NF & $0.652121^{*}$ & 0.146966 & $\begin{array}{l}4.437213 \\
(0.0003)\end{array}$ & 0.483055 & No Random Walk \\
\hline & SI & $0.796134^{*}$ & 0.141804 & $\begin{array}{l}5.614329 \\
(0.0000)\end{array}$ & 0.604123 & No Random Walk \\
\hline \multirow[t]{3}{*}{ Average } & MB & $0.964513^{*}$ & 0.023621 & $\begin{array}{l}40.83324 \\
(0.0000)\end{array}$ & 0.940193 & No Random Walk \\
\hline & NF & $0.98689^{*}$ & 0.016261 & $\begin{array}{l}60.6895 \\
(0.0000)\end{array}$ & 0.97202 & No Random Walk \\
\hline & SI & $0.91929^{\star *}$ & 0.037110 & $\begin{array}{l}24.77193 \\
(0.0306)\end{array}$ & 0.8538 & No Random Walk \\
\hline Sector & SA & $0.953574^{*}$ & 0.025404 & $\begin{array}{l}37.53684 \\
(0.0000)\end{array}$ & 0.929987 & No Random Walk \\
\hline
\end{tabular}


It assumes that all increments are independently drawn from the same distribution with the same mean and variance. The simplest form of the dynamics is the following:

$X_{t}=X_{t-1}+\mu_{t}, \quad \mu_{t}-\operatorname{IID}\left(0, \delta^{2}\right)$. The objective of this study is to examine the random walk hypothesis in the Beverage stock market. For the analysis the random walk hypotheses are:

Null Hypothesis: $\mathrm{H}_{0}$ : $\mathrm{X}_{\mathrm{t}}$ follows random walk.

Alternative Hypothesis: $\mathrm{H}_{1}: \mathrm{X}_{\mathrm{t}}$ follows no random walk.

$\mathrm{Y}_{\mathrm{i}} \mathrm{t}=\beta \mathrm{o}+\beta_{1} \mathrm{MB}+\beta_{2} \mathrm{NF}+\beta_{3} \mathrm{SI}+\boldsymbol{\mu}_{\mathrm{t}}$

Here $\beta$ 's are the companies Coefficients that are $\beta_{1}$ Murree Brewery (MB), $\beta_{2}$ Nirala MSR Foods Limited (NF) and $\beta_{3}$ Shezan International (SI). Table 1 shows the predictive (OLS) Jarret Model.

The regression results reject the null hypothesis in all cases which indicates that share prices do not follow random walk pattern. The random walk test has been employed individually in each month from January to May in three companies- The Murree Brewery Company Limited, Shehzan International Limited, and Nirala MSR Foods
Limited as well as in aggregate (from January to May) level and estimating the sector as a whole all results reject the Null hypothesis thus indicates there is no random walk. Table 2 shows the coefficient of variation approach $(\boldsymbol{\delta} \mid \bar{X} * \mathbf{1 0 0})$ to observe the consistency among the three companies' share prices.

Table 2: Coefficient of variations

\begin{tabular}{llll}
\hline & MB & NF & SI \\
\hline Mean & 719.0363 & 18.45787 & 839.8613 \\
Standard deviation & 132.7095 & 4.514492 & 63.94719 \\
Coefficient of variation & 23.67108 & 19.27623 & 7.232945 \\
\hline
\end{tabular}

The results show that among three companies Murree Brewery is least consistent as compared to Nirala food and Shehzan International. So, as a rational and risk averse investor the Shehzan International is a better option for Investment. Figure 1 shows the share price per day of beverages companies.

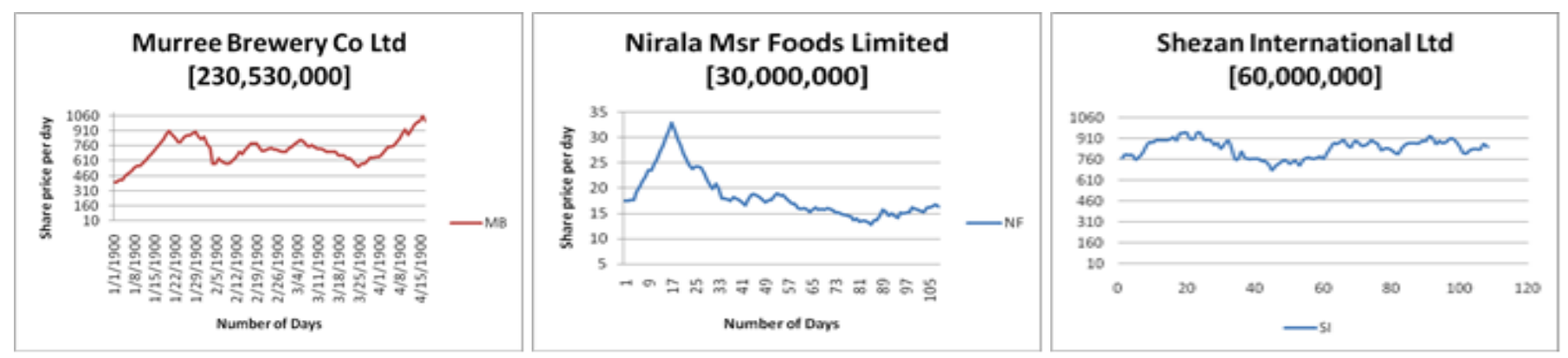

Fig. 1. Share price of beverages companies

\section{Conclusion and recommendations}

The results show the predictability of all the share prices so the highest share price among three companies have Murree Brewery but range of variations in share prices of Shehzan International is more consistent. Thus, recommending investment in Shehzan International. Moreover beverage sector shows an efficient market. On the basis of our different test of Randomness of stock prices of three companies, it is concluded that Beverage sector do not follow Random walk model. Investors can easily predict the future outcome of stocks by applying technical analysis. There is evidence of Day of week effect as Monday has lower return than other days of week return of Shezan International. An investor can sell share in mid of every week and can purchase at lower price in start of every week in order to get profit. As an Investor it is more rational, risk minimization strategy and profitable mode to purchase share of Shehzan International in start of every Month and sell them in end days of month.

\section{References}

Darrat, A. F., and Zhong, M., "On Testing the Random-walk Hypothesis: A Model Comparison Approach", 2000.

Kim, M. J., Nelson, R. C., and Startz, R., 1991, "Mean reversion in stock prices? A reappraisal of the empirical evidence", The Review of Economic Studies, 58, 515-528.

Ming, L. M., Nor, F. M., and Guru, B. K., "Random Walk and Technical Trading Rules: Some Evidence from Malaysia", 2000.

Mishra, A., Mishra, V., and Smyth, R. (2014). The Random-Walk Hypothesis on the Indian Stock Market. ISSN 1441-5429. Discussion Paper 07/14.

Mookerjee, R. and Q. Yu, 1999, "An Empirical Analysis of the Equity Markets In China," Review of Financial Economics, 8, 41-60.

Pant and Bishnoi (2002). Testing Random Walk Hypothesis for Indian Stock Market Indices. Nirma Institute of Management, Ahmedabad.

Wu, S. N., 1996, "The Analysis of the Efficiency of Securities Market in Our Country," Jin Ji Yan Jiu (Economics Research, in Chinese). 